nephron

Practice
Nephron 2015;131:153-160

DOI: $10.1159 / 000440867$
Received: July 23, 2015

Accepted: September 3, 2015

Published online: September 22, 2015

\title{
Acute Kidney Injury and Renal Recovery with the Use of Aminoglycosides: A Large Retrospective Study
}

\author{
François Paquette $^{a} \quad$ Amélie Bernier-Jean $^{a}$ Véronique Brunette ${ }^{b}$ \\ Hélène Ammann ${ }^{c}$ Valéry Lavergne ${ }^{d}$ Vincent Pichette $^{e}$ Stéphan Troyanov $^{a}$ \\ Josée Bouchard ${ }^{a}$ \\ ${ }^{a}$ Division of Nephrology and ${ }^{b}$ Division of Internal Medicine, Department of Medicine, ${ }^{\mathrm{C}}$ Department of Medical Biology \\ and ${ }^{\mathrm{d}}$ Division of Medical Microbiology and Infectious Diseases, Department of Medical Biology, Sacre-Coeur Hospital of \\ Montreal, ' Division of Nephrology, Department of Medicine, Maisonneuve-Rosemont Hospital, Montreal, Que., Canada
}

\section{Key Words}

Acute kidney injury · Aminoglycoside · Gentamicin .

Outcomes $\cdot$ Renal recovery $\cdot$ Tobramycin

\begin{abstract}
Background: Recent acute kidney injury (AKI) guidelines, based on studies performed a decade ago, recommend avoiding aminoglycosides (AGs) in patients at risk of AKI. Whether present patient characteristics and management have changed this risk is uncertain. We determined the current incidence, risk factors and outcomes of AG-AKI. Methods: We retrospectively identified adult patients who received gentamicin or tobramycin for $\geq 5$ days in 2 large university-affiliated centers, excluding critically ill and dialysis patients. We assessed the incidence of Risk, Injury, Failure, Loss and End-stage kidney disease criteria of AKI risk and then matched each AKI to 2 controls of same age and gender to determine factors associated with AG-AKI and its recovery, defined by a creatinine within $150 \%$ of baseline by 21 days. Results: Since 2001, the frequency of AG administration and dosing declined, but the incidence of AG-AKI remained constant. Of the 562 patients who received $A G$ for $\geq 5$ days, 65 (12\%) developed AG-AKI after 11 (IQR 8-15) days,
\end{abstract}

with 56, 29 and $15 \%$ having stages 1, 2 and $3 \mathrm{AKI}$, respectively. We matched these to 130 controls. In this nested casecontrol study, independent AKI risk factors were vancomycin coadministration, high AG trough levels and heart failure. AG-AKI compared to AG exposure without AKI was associated with greater mortality. Renal recovery occurred in 51\% of the AKI patients and was less likely with heart failure and higher AKI severity. Conclusion: AG administration has recently decreased but the risk of AKI remained unchanged and half of the patients did not recover. Vancomycin coadministration, high AG trough levels and heart failure independently predicted AKI.

() 2015 S. Karger AG, Basel

\section{Introduction}

Acute kidney injury (AKI) is associated with higher mortality [1-4], prolonged hospital durations and a higher likelihood of developing chronic kidney disease (CKD) [4, 5]. Aminoglycosides (AGs) are a well-known cause of

J.B. and S.T. co-directed the study.

\section{KARGER 125}

(c) 2015 S. Karger AG, Base

$1660-8151 / 15 / 1313-0153 \$ 39.50 / 0$

E-Mail karger@karger.com

www.karger.com/nef
Dr. Josée Bouchard

Hôpital du Sacré-Coeur de Montréal

5400 Gouin Blvd West

Montréal, QC H4J 1C5 (Canada)

E-Mail josee.bouchard.1@umontreal.ca 
nephrotoxic AKI [6-8]. These antibiotics are currently most often used to treat some endocarditis or multidrug resistant infections, and they accumulate in proximal tubular cells where they disrupt phospholipid metabolism, leading to tubular epithelial cell death and acute tubular necrosis $[9,10]$. Associated renal vasoconstriction and mesangial contraction also contribute to impair kidney function [7]. Consequently, the 2012 Kidney Disease: Improving Global Outcomes (KDIGO) AKI guidelines recommend avoiding AG in patients at risk of or with AKI, unless no suitable, less nephrotoxic therapeutic alternatives are available.

Due to increasing rates of multidrug resistant infections, AGs are still prescribed and their frequency of administration needs to be better delineated. In addition, the side effects associated with the prescription of alternative antibiotic agents need to be balanced against those associated with AG. A recent multicenter study reported a sharp decline in AG use over the last decade and a parallel increase in quinolone prescription, which was associated with greater gram-negative bacilli resistance to quinolone [11]. The use of quinolone has also clearly been associated with Clostridium difficile-associated diarrhea [12]. Similarly, with a higher utilization of broad spectrum B-lactams, the rates of multidrug resistant infections and Clostridium difficile-associated diarrhea have also increased [13-15].

Gentamicin and tobramycin are the most commonly used AG, with amikacin typically reserved for complex and multiresistant infections $[6,11,16]$. Typically, nonoliguric AKI occurs after 5 days of treatment $[6,8,13]$, and the incidence of AG-induced AKI varies between 5 and $25 \%$ depending on the definition employed $[7,9,17-$ 21]. Reported risk factors associated with AKI include older age, CKD, liver disease, diabetes, hypotension, hypoalbuminemia, concomitant nephrotoxic drugs, administration of iodinated contrast, duration of therapy, high through and peak levels, cumulative dose and multipledaily administration [7-10, 17, 20-24]. Few studies have simultaneously addressed these risk factors in multivariate analyses [8,20-22, 24], and most were performed over a decade ago. Their findings may not apply to current practice.

Over the last years, increasing attention has been given to renal outcomes following AKI [25-27]. Limited clinical data exists on renal recovery from AG-AKI [17, 21, 28]. Although irreversible kidney damage seemed uncommon in animals [29], an absence of renal recovery has been observed in humans $[17,28]$ even after a single dose [10]. Clinical predictors of renal recovery following AG-AKI remain unknown.
In light of changing trends in antibiotic use, complications and resistance to quinolone and broad spectrum $\beta$-lactams and costs of newer drugs, AG will remain a valuable therapeutic option for some patients. Identifying the current risk factors of AG-associated nephrotoxic $\mathrm{AKI}$ and renal recovery are essential to lessen the burden of AG-AKI and its associated complications. We sought to determine the risk factors of AG-AKI and absence of renal recovery in patients treated with AG in 2 centers.

\section{Material and Methods}

\section{Study Design}

We performed a retrospective cohort study at 2 university-affiliated centers (Hôpital du Sacré-Coeur de Montréal [HSCM] and Hôpital Maisonneuve-Rosemont [HMR]) to assess the frequency of gentamicin and tobramycin administration for a minimal period of 5 consecutive days, when the risk of AKI significantly increases $[6,8$, 13]. In all identified exposed individuals, we verified whether AKI had developed. We then performed a nested case-control study, pairing AG-AKI cases to 2 controls of same sex and age ( \pm 5 years). We followed the STROBE guidelines for case-control studies. Each centers' Ethics Review Board approved the study. Written consent was waived because of the retrospective observational nature of the study.

\section{Patient Selection}

We identified patients by assessing all serum gentamicin and tobramycin levels. At HSCM, gentamicin and tobramycin levels were available between April 2001 and March 2015, and at HMR, between December 2005 and April 2013. Screened individuals with at least 2 AG results $\geq 72 \mathrm{~h}$ apart and those who received $\geq 5$ continuous days of AG were reviewed to identify AKI cases. We excluded individuals who were $\leq 18$ years of age, without serum creatinine levels or on dialysis. We also excluded critically ill patients, as well as patients with other causes of AKI (e.g., acute gastroenteritis) suspected by chart review or by one of the investigators (V.B. or F.P.). This process was performed prior to the analyses of the results.

\section{Data Collection}

We collected data on demographics and past medical history, including baseline kidney function, diabetes, hypertension, liver disease, heart failure, chronic obstructive pulmonary disease, coronary artery disease, peripheral artery disease and cancer, including the type of cancer. We noted the initial and total dose of gentamicin or tobramycin, timing and frequency of administration, total duration of AG administration and duration prior to AKI, and the highest trough and peak levels, both prior to AKI and over the entire administration period. We also recorded the use of the following drugs over the study period: non-steroidal anti-inflammatory drugs, angiotensin converting enzyme inhibitor or angiotensin receptor blockers, diuretics, acyclovir, calcineurin inhibitors and vancomycin, and highest trough and peak vancomycin levels. We collected data on surgical status, type of infection, administration of iodinated contrast agent, minimal mean arterial pressure during AG exposure and albumin levels during the study period. Outcomes included AKI stages, renal recovery, length of hospital stay and mortality. 


\section{Definitions}

AG-induced AKI was defined by $a \geq 50 \%$ increase in serum creatinine occurring after $\geq 5$ days of AG initiation until a maximum of 7 days after cessation $[8,30]$. This definition is a modification of the Risk, Injury, Failure, Loss and End-stage kidney disease (RIFLE) serum creatinine AKI diagnosis criterion to include the timing of AG exposure. Glomerular filtration rate was estimated using the CKD epidemiology collaboration equation [31]. Heart failure was defined by a history of acute pulmonary edema or by a left ventricular ejection fraction lower than 50\% [32], and liver disease by the presence of chronic hepatitis, cirrhosis or cholestasis. $\mathrm{Pa}$ tients with AKI were classified according to their most severe stage of AKI using the RIFLE serum creatinine classification [30]. Briefly, stage 1 occurs when creatinine increases by $150-199 \%$, stage 2 , when creatinine increases by $200-299 \%$, and stage 3 , when creatinine increases by $\geq 300 \%$ or $\geq 354 \mu \mathrm{mol} / \mathrm{l}$ with a rise of $\geq 44 \mu \mathrm{mol} / \mathrm{l}$. We defined renal recovery by a decrease in serum creatinine to a level $<150 \%$ of baseline creatinine within 21 days after AG cessation [33].

\section{Statistical Analyses}

Continuous variables are presented as mean \pm SD or median and interquartile range (IQR) and compared using the $t$ test or the Mann-Whitney U test, as appropriate. Categorical variables are presented as proportions and compared using the $\chi^{2}$ test. We reported the prescription of AG levels per 1,000 admissions for each center and used the Pearson correlation to address change in the rate of AG prescription over time (trend test).

Within our nested case-control study, we determined whether each variable was associated with AKI and performed a conditional logistic regression [34] to determine independent risk factors of AKI using variables with a $p$ value $<0.20$ by univariate analysis. We used a conditional forward method of variable entry. For these analyses, we used data on duration of AG use, as well as peak and trough levels before AKI diagnosis only. We considered the same variables to determine factors associated with renal recovery, except that we used the total dose and duration of AG administration, as well as the highest trough and peak levels over the entire follow-up, disregarding the timing of AKI diagnosis. Statistical tests were 2 -sided and $\mathrm{p}$ values $<0.05$ was considered significant (SPSS statistics 20.0, IBM, Armonk, N.Y.).

\section{Results}

\section{Frequency of AG Administration and Incidence of AKI}

We identified 3,220 and 2,297 individuals who received either gentamicin or tobramycin with drug dosing during the study period at HSCM and HMR, respectively. The frequency of AG administration significantly decreased over time (fig. 1). Approximately $10-15 \%$ of patients who initially received AG were still on the same medication after 5 days, and this rate remained constant over time (fig. 1). After excluding individuals receiving $<4$ days of AG, children and critically ill patients on di-

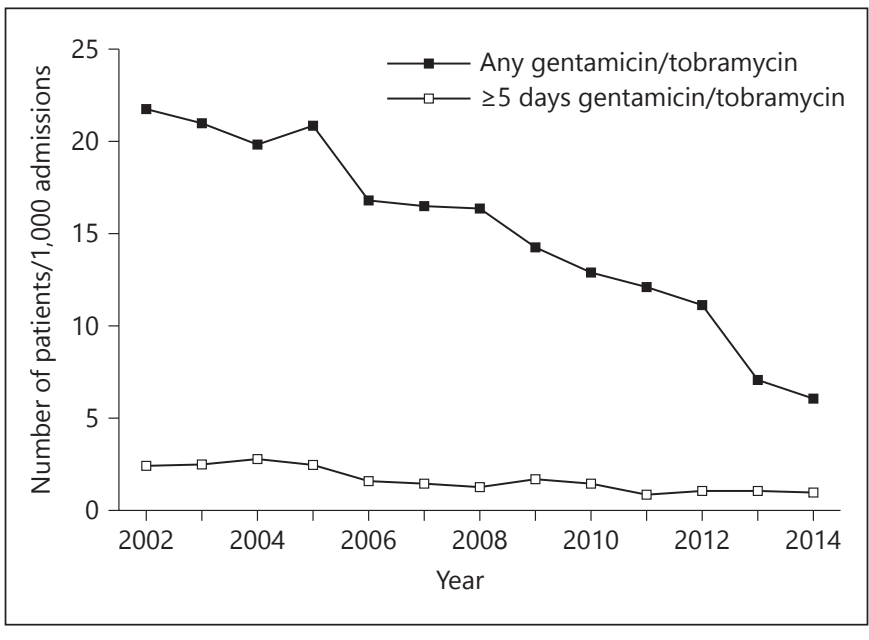

Fig. 1. Prescription of gentamicin and tobramycin over time. The incidence of AG prescription for any duration and for at least 5 days, dropped significantly during the study period ( $\mathrm{p}<0.001$ for both curves over time, trend test).

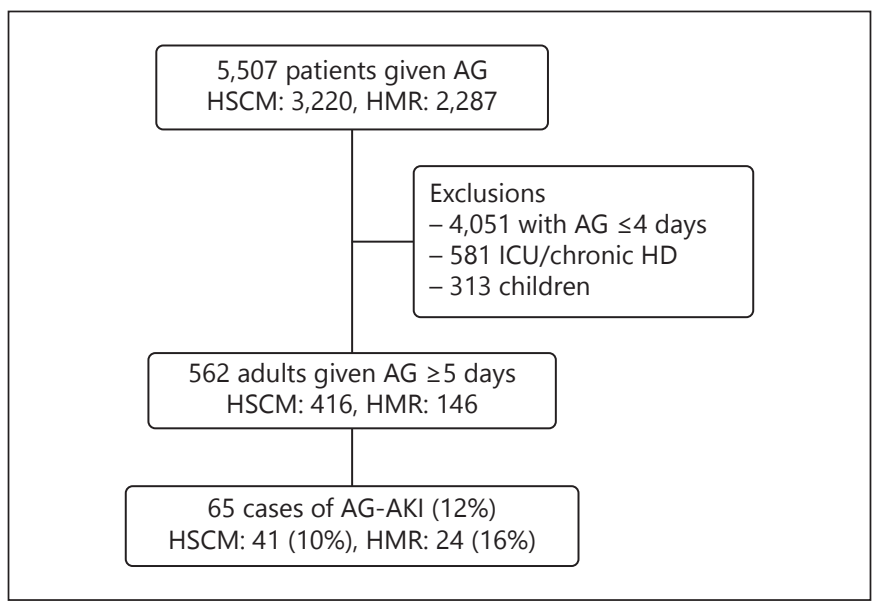

Fig. 2. Patient selection and incidence of AKI. HD = Hemodialysis; ICU $=$ intensive care unit.

alysis, there were 562 adults exposed to at least 5 days of AG (fig. 2), including 65 AKI (12\%) attributed to AG administration. The incidence of AKI did not change over time but was slightly higher in one center than the other (HMR: 16\%, HSCM: 10\%, p = 0.03).

\section{Nested Case-Control Study Population}

We then matched these 65 AKI cases to 2 controls of same age and gender (table 1). Within this nested casecontrol study, the median age was 71 years (IQR 58-81), and $46 \%$ were male. Most patients were treated with gentamicin (82\%). The median duration of AG administra- 
Table 1. Characteristics of patients treated with AGs for at least 5 days in the nested case-control study

\begin{tabular}{|c|c|c|c|}
\hline & AKI $(n=65)$ & Non-AKI (n = 130) & $\mathrm{p}$ value \\
\hline Age, years & 70 (IQR 57-82) & 71 (IQR 58-81) & $0.99 *$ \\
\hline Gender, male, $\%$ & 46 & 46 & $1^{*}$ \\
\hline Baseline creatinine, $\mu \mathrm{mol} / \mathrm{l}$ & 80 (IQR 64-98) & 80 (IQR 62-95) & 0.77 \\
\hline Baseline GFR, $\mathrm{ml} / \mathrm{min} / 1.73 \mathrm{~m}^{2}$ & 78 (IQR 64-92) & 78 (IQR 60-100) & 0.79 \\
\hline Albumin, $g / 1$ & $31 \pm 6$ & $32 \pm 8$ & 0.42 \\
\hline $\mathrm{CAD}, \%$ & 29 & 22 & 0.30 \\
\hline $\mathrm{PAD}, \%$ & 11 & 11 & 0.96 \\
\hline COPD, \% & 15 & 19 & 0.51 \\
\hline Heart failure, $\%$ & 29 & 10 & 0.001 \\
\hline Liver disease, \% & 7.7 & 0.8 & 0.009 \\
\hline Diabetes, \% & 40 & 35 & 0.53 \\
\hline Hypertension, \% & 52 & 52 & 1 \\
\hline Active cancer, \% & 28 & 30 & 0.74 \\
\hline Hematological cancer, \% & 19 & 19 & 1 \\
\hline NSAIDS, $\%$ & 7.7 & 6.9 & 0.84 \\
\hline ACEI/ARB, \% & 34 & 26 & 0.26 \\
\hline Vancomycin, \% & 54 & 18 & $<0.001$ \\
\hline Acyclovir, \% & 7.9 & 3.9 & 0.24 \\
\hline Diuretics, $\%$ & 52 & 34 & 0.01 \\
\hline Calcineurin inhibitors, $\%$ & 6.3 & 5.5 & 0.81 \\
\hline Surgery, \% & 17 & 15 & 0.78 \\
\hline Gentamicin/tobramycin, \% & $85 / 15$ & $81 / 19$ & 0.51 \\
\hline Daily dosing, \% & 22 & 25 & 0.55 \\
\hline Duration of AG use, days & 14 (IQR 10-19) & 10 (IQR 7-15) & 0.001 \\
\hline Duration of AG use until AKI, days & $11($ IQR $8-15)$ & 10 (IQR 7-15) & 0.26 \\
\hline Maximal AG trough, $\mu \mathrm{g} / \mathrm{ml}$ & 2.0 (IQR 1.2-2.7) & 1.3 (IQR $0.8-1.9$ ) & $<0.001$ \\
\hline Maximal AG trough, $\geq 2 \mu \mathrm{g} / \mathrm{ml}, \%$ & 51 & 20 & $<0.001$ \\
\hline Maximal AG peak, $\mu \mathrm{g} / \mathrm{ml}$ & 5.8 (IQR 4.4-9.1) & 6.0 (IQR 4.3-7.7) & 0.36 \\
\hline Iodinated contrast, $\%$ & 25 & 23 & 0.81 \\
\hline Minimal MAP, mm Hg & $102 \pm 16$ & $105 \pm 14$ & 0.20 \\
\hline Type of infection, $\%$ & & & 0.006 \\
\hline Endocarditis & 42 & 19 & \\
\hline Febrile neutropenia & 15 & 10 & \\
\hline Urinary tract & 14 & 26 & \\
\hline Lung & 12 & 15 & \\
\hline Abdominal & 5 & 16 & \\
\hline Musculoskeletal & 9 & 13 & \\
\hline Other & 3 & 2 & \\
\hline
\end{tabular}

Data were missing in $<1 \%$ of records. $\mathrm{ACEI}=$ Angiotensin converting enzyme inhibitor; $\mathrm{ARB}=$ angiotensin receptor blockers; $\mathrm{CAD}=$ coronary artery disease; $\mathrm{COPD}=$ chronic obstructive pulmonary disease; GFR = glomerular filtration rate; $\mathrm{MAP}=$ mean arterial pressure; NSAIDs = non-steroidal anti-inflammatory drugs; $\mathrm{PAD}=$ peripheral artery disease.

tion was 11 days (IQR 8-16). AKI occurred 11 days (IQR 8-15) after AG administration. Endocarditis (26\%), urinary tract infections (22\%) and febrile neutropenia (12\%) were among the most common types of infection, and only $16 \%$ of patients underwent surgery. Twenty-four percent received initial single-daily doses of antibiotics ( $14 \%$ in endocarditis and $28 \%$ in other types of infection; $\mathrm{p}=0.04)$.
Thirty-six out of 65 patients had AG administration stopped at the time of AKI diagnosis. Within those who continue to receive $A G$, the median duration was 5.0 days (IQR 2.0-11.0) from AKI diagnosis. Maximal trough levels were significantly higher in AKI (levels before AKI diagnosis only) compared to non-AKI patients (2.0 (IQR $1.2-2.7$ ) vs. 1.3 (IQR $0.8-1.9) \mu \mathrm{g} / \mathrm{ml} ; \mathrm{p}<0.001$ ). The best cut-off point to predict AKI was a trough level of $\geq 2.0 \mu \mathrm{g} /$ 
Table 2. Multivariate risk factors of AKI in patients treated with AG for at least 5 days in the nested case-control study $(n=195)$

\begin{tabular}{lccc}
\hline & OR & $95 \%$ CI & p value \\
\hline $\begin{array}{l}\text { Vancomycin } \\
\text { Trough level prior to }\end{array}$ & 5.19 & $2.24-12.01$ & $<0.001$ \\
$\quad$ AKI $\geq 2.0 \mu \mathrm{g} / \mathrm{ml}$ & 3.44 & $1.57-7.54$ & 0.002 \\
Heart failure & 3.25 & $1.08-9.76$ & 0.04 \\
\hline
\end{tabular}

The following variables were included in the multivariate model $(p<0.20)$ : heart failure, liver disease, site of infection, vancomycin, diuretic and maximal trough levels before AKI (dichotomized). Liver disease was the fourth independent risk factor with an infinite OR. However, in light of its very low prevalence in this cohort, the interpretation of this result is uncertain. Removing liver disease from the model did not significantly change the results in the table.

ml (AUC 0.68 (95\% CI $0.60-0.76$ ); sensitivity of $51 \%$ and specificity of $80 \%)$. AKI patients were also more likely to suffer from heart failure, liver disease and to have received diuretics and vancomycin. However, trough vancomycin levels were similar in patients with and without AKI $(p=0.60)$. Patients with endocarditis had significantly more AKI (53 vs. $27 \%, \mathrm{p}=0.001$ ). Tobramycin (over gentamicin) was given to $15 \%$ of AKI and $19 \%$ of non-AKI patients $(\mathrm{p}=0.51)$. The total dose of gentamicin and tobramycin administered did not differ between AKI and non-AKI patients as the percentage receiving daily doses. There were also no differences in the duration of AG administration before AKI in AKI patients and the total duration of AG in non-AKI patients (11 (IQR 8-15) vs. 10 days (IQR 7-15); $\mathrm{p}=0.26$ ).

\section{Independent Risk Factors for AKI}

Using conditional logistic regression, the independent risk factors associated with AKI were heart failure, concomitant vancomycin administration and high trough levels (table 2). Liver disease was the fourth independent risk factor with an infinite OR. However, in light of its very low prevalence in this cohort, the interpretation of this result is uncertain. Removing liver disease from the model did not significantly change the results. The prevalence of these independent risk factors did not change over time.

\section{Outcomes and Renal Recovery}

The maximal AKI stage was 1 for 56\%, 2 for $29 \%$ and 3 for $15 \%$ of patients. Hospital mortality was higher in AKI patients compared to non-AKI patients (28 vs. $14 \%$, $\mathrm{p}=0.02$ ). The hospital length of stay was 34 days (IQR

Acute Kidney Injury and Recovery with

AG
19-66) in AKI patients compared to 28 (IQR 10-54) in non-AKI patients $(\mathrm{p}=0.03)$.

Only 51\% (33 of 65) of all AKI patients recovered their kidney function within 21 days from AG cessation, with a median duration of AKI of 7 days (IQR 4-12). Similarly, $51 \%$ of AKI survivors recovered their kidney function after 8 days (IQR 5-13). Patients with a history of heart failure were less likely ( 14 vs. $60 \%, p=0.002$ ), whereas those with cancer ( 81 vs. $37 \%, \mathrm{p}=0.002$ ) or those receiving intravenous acyclovir (100 vs. $44 \%, \mathrm{p}=0.02$ ) were more likely to recover their kidney function. A lower severity of AKI was also associated with renal recovery. Sixty-four, 36 and $0 \%$ of patients with stages 1,2 and 3 AKI, respectively, recovered their kidney function $(\mathrm{p}=$ 0.006).

\section{Discussion}

AGs are a well-known preventable cause of AKI [6-8], which is clearly associated with adverse outcomes in critically and non-critically ill populations [1-5]. Consequently, the KDIGO AKI guidelines recommended avoiding AG in patients at risk or with AKI, if possible [9]. We found that AG utilization decreased over the last decade, a finding consistent with results from other multicenter studies $[11,35]$.

Based on modified RIFLE serum creatinine criteria including the timing of AG administration, and with clinical adjudication of all cases [30], the incidence of AKI in our cohort was $12 \%$. Of note, our population included patients on at least 5 days of AG and a large proportion of patients (76\%) received multiple-daily AG doses. The incidence of AKI in our cohort was lower or similar to previously reported rates with shorter duration of treatment and single-daily AG administration using the same AKI definition (12-24\%) [17, 19, 21].

Our nested case-control study identified heart failure, concomitant use of vancomycin and high trough levels before AKI as independent risk factors of AG-induced AKI. AG-AKI was also associated with a higher morbidity and mortality. To our knowledge, this is the first clinical study to report heart failure as an independent risk factor for AKI associated with AG administration while adjusting for diuretic use and other main risk factors [28, 36]. There is a rationale supporting the association of heart failure and AKI with AG administration, as reduced renal blood flow may aggravate tubular injury related to AG, by limiting oxygen and nutrient availability and facilitating oxidative stress $[6,7,37]$. Liver disease was also 
predictive of AKI by univariate analysis but given its very low prevalence in our study, the conditional logistic regression was unable to calculate a specific OR so its independent value would need confirmation. Interestingly, advanced liver disease is also associated with reduced renal blood flow [24], highlighting the importance of an adequate renal blood flow to limit AG-induced AKI.

Regarding other risk factors of AKI, our results provide further confirmation that concomitant vancomycin $[24,38,39]$ and high trough AG levels $[8,17]$ are independent risk factors of AKI. This last finding is in accordance with the KDIGO AKI guidelines, supporting cautious dosing and therapeutic drug monitoring to reduce the risk of AKI [9]. In our cohort, the optimal cut-off for AG trough level predicting AKI was exactly $\geq 2.0 \mu \mathrm{g} / \mathrm{ml}$, as recently reviewed [13]. This threshold is still debated $[13,40,41]$, as high levels could be the result and not the cause of AKI [6]. In our study, we purposely assessed trough levels before AKI diagnosis to address this limitation.

There are limited clinical data on the rate of renal recovery from AG-induced AKI $[21,28]$. We found that renal recovery, defined by a decrease in serum creatinine to $<150 \%$ of baseline within 3 weeks after AG cessation, occurred in only $51 \%$ of patients. Reviews and animal studies have reported that AG-AKI is reversible within a few weeks $[13,29]$. To our knowledge, only 2 other human studies evaluated the rate of renal recovery post AG-AKI. One showed a complete renal recovery in 21 of 27 AKI survivors at hospital discharge; however, renal recovery was not defined [21]. The other study, performed 30 years ago, reported that 16 out of 26 AG-AKI patients had a creatinine level at or below their baseline after 2 months, but the AKI definition was not standardized [28]. One study mentioned a significant reduction in creatinine levels before discharge without further details [17]. Another key finding of our study is that renal recovery does not occur as often as previously reported [29], at least in those who receive $A G$ for $\geq 5$ days.

Risk factors associated with the absence of renal recovery in this population are unknown. Traditional risk factors of absence of renal recovery are older age, female gender and the severity of illness and AKI itself [42-45]. In our cohort, higher AKI severity and heart failure were associated with a lower likelihood of renal recovery. The finding that cancer patients are more likely to recover their kidney function may reflect their younger age or 'real' renal recovery, but could also be related to a more rapid loss in muscle mass in this population during hospital stay, leading to a falsely low serum creatinine level
[46]. This finding could also be related to the concomitant administration of acyclovir, as most cancers (61\%) were from hematological origin. Acyclovir is used more commonly in cancer patients and may impair kidney function by precipitating in the renal tubules, a condition usually reversible within a few days [47].

Our study has several strengths. We included patients from 2 centers with different clinical conditions, increasing the generalizability of our results. In addition, as opposed to large database studies where clinical adjudication of AG nephrotoxicity is impossible [10], we reviewed all cases and controls to avoid any ascertainment bias. We purposely paired cases and controls by age and gender to allow teasing out other risk factors of nephrotoxicity, and excluded critically ill patients in whom multiple risk factors for AKI often coexist to facilitate the clinical adjudication of AKI cases [19].

Our study also has limitations. Since all patients required drug and creatinine levels to be included in our study, we could have missed patients with undiagnosed AKI or others where drug levels were not performed. Although this may have slightly lowered the incidence of AG prescription or AG-AKI, It would have been difficult to ascertain the role of other potential risk factors in this population without knowledge of AG levels. We used a modified serum creatinine RIFLE classification to diagnose and stage AKI, as it remains the most validated definition [30], and for consistency as we used this definition in 2009 when we first reported the patterns of prescription of AG in our centers [48]. We also assessed the incidence of AKI with the Acute Kidney Injury Network and the KDIGO definitions, and we did not identify any new case of AKI using these definitions. Finally, we chose to include patients who received at least 5 days of AG since when we designed the study, there were no published data on the possible nephrotoxicity associated with a single dose of AG [10, 49]. We do not know whether our results apply to patients receiving empiric AG treatment for a few days until culture results become available.

\section{Conclusion}

In summary, we showed that despite concerns regarding the resurgence of AG utilization, the frequency of AG administration and dosing decreased over the last decade. Clinicians will therefore have a more limited experience with these agents. The recognition of risk factors associated with AG-AKI is important as they may influence their utilization. In our cohort, high trough levels before 
AKI ( $\geq 2 \mu \mathrm{g} / \mathrm{ml})$, heart failure and vancomycin coadministration were independent risk factors associated with AKI. Of note, 2 of these risk factors are potentially preventable. Future recommendations on AG administration may include additional information on modifiable AG-AKI risk factors. Finally, our study expands on prior knowledge by providing insight on the relatively low percentage of complete renal recovery from AG-AKI and by identifying heart failure as a risk factor for both AKI and absence of renal recovery. Further studies are required to better understand the incidence and the predictors of renal recovery following AG-AKI.

\section{Acknowledgments}

The research efforts of J.B. and S.T. were supported by the Fonds de la Recherche du Québec-Santé. This study was supported by a grant from the Kidney Foundation of Canada. Some of the results of this study have been presented as poster presentations at the 2009 American Society of Nephrology meeting.

\section{Disclosure Statement}

We have no competing financial interest or conflict of interest to declare.

\section{References}

-1 Uchino S, Kellum JA, Bellomo R, Doig GS, Morimatsu H, Morgera S, Schetz M, Tan I, Bouman C, Macedo E, Gibney N, Tolwani A, Ronco C; Beginning and Ending Supportive Therapy for the Kidney (BEST Kidney) Investigators: Acute renal failure in critically ill patients: a multinational, multicenter study. JAMA 2005;294:813-818.

-2 Chertow GM, Burdick E, Honour M, Bonventre JV, Bates DW: Acute kidney injury, mortality, length of stay, and costs in hospitalized patients. J Am Soc Nephrol 2005;16:33653370.

-3 Waikar SS, Curhan GC, Wald R, McCarthy EP, Chertow GM: Declining mortality in patients with acute renal failure, 1988 to 2002 . J Am Soc Nephrol 2006;17:1143-1150.

4 Waikar SS, Liu KD, Chertow GM: Diagnosis, epidemiology and outcomes of acute kidney injury. Clin J Am Soc Nephrol 2008;3:844-861.

$\checkmark 5$ Chawla LS, Amdur RL, Amodeo S, Kimmel PL, Palant CE: The severity of acute kidney injury predicts progression to chronic kidney disease. Kidney Int 2011;79:1361-1369.

6 Humes HD: Aminoglycoside nephrotoxicity. Kidney Int 1988;33:900-911.

7 Lopez-Novoa JM, Quiros Y, Vicente L, Morales AI, Lopez-Hernandez FJ: New insights into the mechanism of aminoglycoside nephrotoxicity: an integrative point of view. Kidney Int 2011;79:33-45.

-8 Moore RD, Smith CR, Lipsky JJ, Mellits ED, Lietman PS: Risk factors for nephrotoxicity in patients treated with aminoglycosides. Ann Intern Med 1984;100:352-357.

9 Kidney Disease: Improving Global Outcomes (KDIGO) Acute Kidney Injury Work Group: KDIGO clinical practice guideline for acute kidney injury. Kidney Int Suppl 2012;2:1138.

10 Bell S, Davey P, Nathwani D, Marwick C, Vadiveloo T, Sneddon J, Patton A, Bennie M, Fleming S, Donnan PT: Risk of AKI with gentamicin as surgical prophylaxis. J Am Soc Nephrol 2014;25:2625-2632.
11 Ababneh M, Harpe S, Oinonen M, Polk RE: Trends in aminoglycoside use and gentamicin-resistant gram-negative clinical isolates in US academic medical centers: implications for antimicrobial stewardship. Infect Control Hosp Epidemiol 2012;33:594-601.

12 Loo VG, Poirier L, Miller MA, Oughton M, Libman MD, Michaud S, Bourgault AM, Nguyen T, Frenette C, Kelly M, Vibien A, Brassard P, Fenn S, Dewar K, Hudson TJ, Horn R, René P, Monczak Y, Dascal A: A predominantly clonal multi-institutional outbreak of Clostridium difficile-associated diarrhea with high morbidity and mortality. $\mathrm{N}$ Engl J Med 2005;353:2442-2449.

13 Destache CJ: Aminoglycoside-induced nephrotoxicity - a focus on monitoring: a review of literature. J Pharm Pract 2014;27:562-566.

14 Xu J, Duan X, Wu H, Zhou Q: Surveillance and correlation of antimicrobial usage and resistance of Pseudomonas aeruginosa: a hospital population-based study. PLoS One 2013; 8:e78604.

15 Hensgens MP, Goorhuis A, Dekkers OM, Kuijper EJ: Time interval of increased risk for Clostridium difficile infection after exposure to antibiotics. J Antimicrob Chemother 2012; 67:742-748.

16 Morata L, Cobos-Trigueros N, Martínez JA, Soriano A, Almela M, Marco F, Sterzik H, Nunez R, Hernández C, Mensa J: Influence of multidrug resistance and appropriate empirical therapy on the 30-day mortality rate of Pseudomonas aeruginosa bacteremia. Antimicrob Agents Chemother 2012;56:4833-4837.

17 Raveh D, Kopyt M, Hite Y, Rudensky B, Sonnenblick M, Yinnon AM: Risk factors for nephrotoxicity in elderly patients receiving once-daily aminoglycosides. QJM 2002;95: 291-297.

18 Wargo KA, Edwards JD: Aminoglycoside-induced nephrotoxicity. J Pharm Pract 2014;27: 573-577.

19 Picard W, Bazin F, Clouzeau B, Bui HN, Soulat M, Guilhon E, Vargas F, Hilbert G, Bouchet
S, Gruson D, Moore N, Boyer A: Propensitybased study of aminoglycoside nephrotoxicity in patients with severe sepsis or septic shock. Antimicrob Agents Chemother 2014; 58:7468-7474.

20 Paterson DL, Robson JM, Wagener MM: Risk factors for toxicity in elderly patients given aminoglycosides once daily. J Gen Intern Med 1998;13:735-739.

21 Selby NM, Shaw S, Woodier N, Fluck RJ, Kolhe NV: Gentamicin-associated acute kidney injury. QJM 2009;102:873-880.

22 Oliveira JF, Silva CA, Barbieri CD, Oliveira GM, Zanetta DM, Burdmann EA: Prevalence and risk factors for aminoglycoside nephrotoxicity in intensive care units. Antimicrob Agents Chemother 2009;53:28872891.

23 Ferriols-Lisart R, Alós-Almiñana M: Effectiveness and safety of once-daily aminoglycosides: a meta-analysis. Am J Health Syst Pharm 1996;53:1141-1150.

24 Bertino JS Jr, Booker LA, Franck PA, Jenkins PL, Franck KR, Nafziger AN: Incidence of and significant risk factors for aminoglycosideassociated nephrotoxicity in patients dosed by using individualized pharmacokinetic monitoring. J Infect Dis 1993;167:173-179.

25 Bagshaw SM, Laupland KB, Doig CJ, Mortis G, Fick GH, Mucenski M, Godinez-Luna T, Svenson LW, Rosenal T: Prognosis for longterm survival and renal recovery in critically ill patients with severe acute renal failure: a population-based study. Crit Care 2005; 9:R700-R709.

26 Coca SG, Singanamala S, Parikh CR: Chronic kidney disease after acute kidney injury: a systematic review and meta-analysis. Kidney Int 2012;81:442-448.

27 Pannu N, James M, Hemmelgarn B, Klarenbach S; Alberta Kidney Disease Network: Association between AKI, recovery of renal function, and long-term outcomes after hospital discharge. Clin J Am Soc Nephrol 2013; 8:194-202. 
28 Matzke GR, Lucarotti RL, Shapiro HS: Controlled comparison of gentamicin and tobramycin nephrotoxicity. Am J Nephrol 1983;3: 11-17.

29 Houghton DC, English J, Bennett WM: Chronic tubulointerstitial nephritis and renal insufficiency associated with long-term 'subtherapeutic' gentamicin. J Lab Clin Med 1988; 112:694-703.

30 Bellomo R, Ronco C, Kellum JA, Mehta RL, Palevsky P; Acute Dialysis Quality Initiative workgroup: Acute renal failure - definition, outcome measures, animal models, fluid therapy and information technology needs: the Second International Consensus Conference of the Acute Dialysis Quality Initiative (ADQI) group. Crit Care 2004;8:R204-R212.

- 31 Levey AS, Stevens LA, Schmid CH, Zhang YL, Castro AF 3rd, Feldman HI, Kusek JW, Eggers P, Van Lente F, Greene T, Coresh J; CKDEPI (Chronic Kidney Disease Epidemiology Collaboration): A new equation to estimate glomerular filtration rate. Ann Intern Med 2009;150:604-612.

32 Yancy CW, Jessup M, Bozkurt B, Butler J, Casey DE Jr, Drazner MH, Fonarow GC, Geraci SA, Horwich T, Januzzi JL, Johnson MR, Kasper EK, Levy WC, Masoudi FA, McBride PE, McMurray JJ, Mitchell JE, Peterson PN, Riegel B, Sam F, Stevenson LW, Tang WH, Tsai EJ, Wilkoff BL; American College of Cardiology Foundation; American Heart Association Task Force on Practice Guidelines: 2013 ACCF/AHA guideline for the management of heart failure: a report of the american college of cardiology foundation/american heart association task force on practice guidelines. J Am Coll Cardiol 2013;62:e147-e239.

- 33 Schentag JJ, Jusko WJ: Renal clearance and tissue accumulation of gentamicin. Clin Pharmacol Ther 1977;22:364-370.
34 Rahman M, Sakamoto J, Fukui T: Conditional versus unconditional logistic regression in the medical literature. J Clin Epidemiol 2003; 56:101-102.

35 Chen IL, Lee CH, Su LH, Tang YF, Chang SJ, Liu JW: Antibiotic consumption and healthcare-associated infections caused by multidrug-resistant gram-negative bacilli at a large medical center in Taiwan from 2002 to 2009 : implicating the importance of antibiotic stewardship. PLoS One 2013;8:e65621.

36 Hennessy S, Leonard CE, Localio AR, Cohen A, Yang W, Cheung L, Strom BL, Herlim M, Feldman HI: Prescriber adherence to pharmacokinetic monitoring service recommendations for aminoglycoside dosing and the risk of acute kidney injury. Int J Clin Pharmacol Ther 2011;49:536-544.

37 Zager RA, Sharma HM: Gentamicin increases renal susceptibility to an acute ischemic insult. J Lab Clin Med 1983;101:670-678.

38 Gerlach AT, Stawicki SP, Cook CH, Murphy C: Risk factors for aminoglycoside-associated nephrotoxicity in surgical intensive care unit patients. Int J Crit Illn Inj Sci 2011;1:17-21.

39 Fraisse T, Gras Aygon C, Paccalin M, Vitrat V, De Wazieres B, Baudoux V, Lechiche C, Vicens A, Sotto A, Pagani L, Gaillat J, Forestier E, Gavazzi G: Aminoglycosides use in patients over 75 years old. Age Ageing 2014;43:676-681.

40 McCormack JP, Jewesson PJ: A critical reevaluation of the 'therapeutic range' of aminoglycosides. Clin Infect Dis 1992;14:320-339.

41 Abdel-Bari A, Mokhtar MS, Sabry NA, ElShafi SA, Bazan NS: Once versus individualized multiple daily dosing of aminoglycosides in critically ill patients. Saudi Pharm J 2011; 19:9-17.

42 Srisawat N, Murugan R, Lee M, Kong L, Carter M, Angus DC, Kellum JA; Genetic and Inflammatory Markers of Sepsis (GenIMS) Study In- vestigators: Plasma neutrophil gelatinase-associated lipocalin predicts recovery from acute kidney injury following community-acquired pneumonia. Kidney Int 2011;80:545-552.

43 Macedo E, Zanetta DM, Abdulkader RC: Long-term follow-up of patients after acute kidney injury: Patterns of renal functional recovery. PLoS One 2012;7:e36388.

44 Lin YF, Ko WJ, Chu TS, Chen YS, Wu VC, Chen YM, Wu MS, Chen YW, Tsai CW, Shiao CC, Li WY, Hu FC, Tsai PR, Tsai TJ, Wu KD; NSARF Study Group: The 90-day mortality and the subsequent renal recovery in critically ill surgical patients requiring acute renal replacement therapy. Am J Surg 2009;198:325332.

45 Bagshaw SM, Mortis G, Godinez-Luna T, Doig CJ, Laupland KB: Renal recovery after severe acute renal failure. Int J Artif Organs 2006;29:1023-1030.

46 Schetz M, Gunst J, Van den Berghe G: The impact of using estimated GFR versus creatinine clearance on the evaluation of recovery from acute kidney injury in the ICU. Intensive Care Med 2014;40:1709-1717.

47 Fleischer R, Johnson M: Acyclovir nephrotoxicity: a case report highlighting the importance of prevention, detection, and treatment of acyclovir-induced nephropathy. Case Rep Med 2010;2010:pii:602783.

48 Brunette V, Lavergne V, Chapdelaine I, Ghannoum M, Ammann H, Troyanov S: Incidence and risk factors of gentamicin nephrotoxicity in a tertiary center from 2001 to 2008. J Am Soc Nephrol 2009;20:595A.

49 Nielsen DV, Fedosova M, Hjortdal V, Jakobsen CJ: Is single-dose prophylactic gentamicin associated with acute kidney injury in patients undergoing cardiac surgery? A matched-pair analysis. J Thorac Cardiovasc Surg 2014;148: 1634-1639. 